\section{Intraventricular ciprofloxacin usage in treatment of multidrug-resistant central nervous system infections: report of four cases}

\author{
Ayşe Karaaslan, Eda Kepenekli Kadayifçi, \\ Ozden Turel, Demet Gedikbaşi Toprak, \\ Ahmet Soysal, Mustafa Bakir \\ Department of Pediatric Infectious \\ Diseases, Marmara University School of \\ Medicine, Istanbul, Turkey
}

\begin{abstract}
In recent years, multidrug-resistant microorganisms appear as important nosocomial pathogens which treatment is quite difficult. As sufficient drug levels could not be achieved in cerebrospinal fluid during intravenous antibiotic therapy for central nervous system infections and due to multidrug-resistance treatment alternatives are limited. In this study, four cases of central nervous system infections due to multidrug-resistant microorganisms who were successfully treated with removal of the devices and intraventricular ciprofloxacin are presented. In conclusion, intraventricular ciprofloxacin can be used for treatment of central nervous system infections if the causative microorganism is sensitive to the drug and no other alternative therapy is available.
\end{abstract}

\section{Introduction}

Increasing prevalence of multidrug-resistant (MDR) microorganisms has led to a rise in clinically significant nosocomial infections with these organisms and an increasing therapeutic difficulty. Central nervous system (CNS) infections are even more difficult to treat due to difficulty of reaching therapeutic drug concentrations in the cerebrospinal fluid. 1

The recommended treatment in CNS shunt infections is similar to the treatment in bacterial meningitis. The specific indications of intraventricular treatment are not welldefined.2 However, intraventricular (IVT) treatment might become necessary in cases in which infected shunt could not be removed or bacterial eradication could not be achieved with intravenous therapy. ${ }^{2-4}$ Theoretically higher levels of antibiotics could be achieved by direct administration of antibacterial agents into the ventricle. Although fluoro- quinolones have potential side effects, they are important drugs in treatment of numerous MDR life-threatening infections. In the present article four cases of CNS infections caused by MDR microorganisms, one of them related with ventriculoperitoneal (V-P) shunt and one of them related with external ventricular drainage (EVD) tube, who were successfully treated with IVT ciprofloxacin are presented. In our cases, inspite of removal of the devices and systemic antibiotic therapy, bacterial growth continued in cerebrospinal fluid (CSF) cultures and IVT ciprofloxacin was administered and rapid bacterial irradication was achieved and no side effects were observed during and after treatment.

\section{Case Report \#1}

A thirty-days-old male infant admitted to the hospital with the complaints of fever, decreased sucking and restlessness. In history, V-P shunt was placed at 23rd day of birth because of hydrocephalus. His CSF samples showed abundant leukocytes and gram negative bacilli. CSF glucose level was $3 \mathrm{mg} / \mathrm{dL}$, and protein level was $197 \mathrm{mg} / \mathrm{dL}$. The patient was diagnosed as V-P shunt infection, therefore shunt was removed and EVD was placed. Meropenem was started as empirical antibiotic therapy. Cerebrospinal fluid culture revealed extended spectrum beta-lactamase (ESBL) producing Klebsiella pneumoniae which was sensitive to meropenem, amikacin and ciprofloxacin. Klebsiella pneumoniae was persisted in CSF at $8^{\text {th }}$ day of IV meropenem treatment, so IVT ciprofloxacin ( $1 \mathrm{mg} / \mathrm{kg} /$ day) was added to treatment. CSF cultures remained sterile 48 hours after addition of IVT ciprofloxacin. Improvement was observed in both clinical findings and CSF findings of the patient after 6 weeks' meropenem and 3 weeks' IVT ciprofloxacin therapy. V-P shunt was re-placed and the patient was discharged.

\section{Case Report \#2}

A two-months-old male infant transferred to our hospital because of Pseudomonas aeruginosa meningitis unresponsive to intravenous meropenem (3 weeks), piperacillin (3 weeks), ciprofloxacin (8 days) and amikacin (8 days) combination therapies. Upon admission CSF glucose level was $0 \mathrm{mg} / \mathrm{dL}$, protein level was $128 \mathrm{mg} / \mathrm{dL}$ and there were 100 cells $/ \mathrm{mm}^{3}$ in microscopic examination. CSF culture revealed $P$. aeruginosa which was resistant to all antibiotics except ciprofloxacin and colistin. EVD tube was inserted due to hydrocephalus. Intravenous ciprofloxacin and
Correspondence: Ahmet Soysal, Marmara University School of Medicine, Department of Pediatric Infectious Diseases, Mimar Sinan Street 41, Fevzi Cakmak Mah., Ust Kaynarca, Pendik, Istanbul, Turkey.

Tel.: +90.532.448.3571 - Fax: +90.216.657.0695.

E-mail: asoysal@marmara.edu.tr

Key words: intraventricular therapy, ciprofloxacin, children.

Contributions: the authors contributed equally.

Conflict of interests: the authors declare no potential conflict of interests.

Received for publication: 30 August 2014.

Revision received: 11 October 2014.

Accepted for publication: 8 November 2014

This work is licensed under a Creative Commons Attribution NonCommercial 3.0 License (CC BYNC 3.0).

(C) Copyright A. Karaaslan et al., 2014

Licensee PAGEPress, Italy

Pediatric Reports 2014; 6:5619

doi:10.4081/pr.2014.5619

meropenem therapy were started in accordance to the microbiological synergy test results. Since that time colistin was not available in our country. For this reason, IVT ciprofloxacin ( $1 \mathrm{mg} / \mathrm{kg} /$ day) was also started via EVD tube. CSF cultures remained sterile after 8 weeks of intravenous meropenem and ciprofloxacin and 25 days IVT ciprofloxacin therapies. The patient was discharged after V$P$ shunt insertion.

\section{Case Report \#3}

A nine-years-old female who had cyanotic congenital heart disease transferred to our hospital because of brain abscess unresponsive to vancomycin, cefotaxime and metranidazole combination therapy for 3 weeks. Upon admission, there was no leukocyte in direct examination of CSF and no bacteria on gram staining. CSF protein level was $64 \mathrm{mg} / \mathrm{dL}$, glucose level was $69 \mathrm{mg} / \mathrm{dL}$. On echocardiography a vegetation on tricuspit leaflet was detected. Cranial abscess was drained surgically and EVD tube was inserted. Antibiotic therapy was changed to intravenous ceftriaxone, metranidazole and IVT gentamicin, emprically. Blood, CSF and brain abcess cultures remained sterile. At the 14th day of therapy the patient had clinical worsening. CSF glucose level was $38 \mathrm{mg} / \mathrm{dL}$, protein level was $94 \mathrm{mg} / \mathrm{dL}$ and there were 130 leukocytes $/ \mathrm{mm}^{3}$ in microscopic examination. 
Vancomycin-resistant Enterococcus feaceum was isolated in CSF and blood cultures and then according to the antibiotic susceptibility test results ciprofloxacin [intravenous and IVT (1 $\mathrm{mg} / \mathrm{kg} /$ day for ten days)] and tetracycline (P0) therapies were started with the diagnosis of medical device-associated meningitis. At that time linezolid was not available in our country. During follow-up, her clinical condition was improved and CSF and blood cultures remained sterile. Antibiotic therapy was continued up to 6 weeks. The vegetation on tricuspid valve got smaller and became calcified. The brain abscess completely regressed. V-P shunt was inserted due to hydrocephalus and she was discharged.

\section{Case Report \#4}

A fifty-three-days old male infant admitted to our hospital with the complaints of decreased sucking and awareness. In history, he had an operation for meningomyelocele on the second day of his life. On admission CSF glucose level was $1 \mathrm{mg} / \mathrm{dL}$, protein level was $180 \mathrm{mg} / \mathrm{dL}$ and there were 500 leukocytes $/ \mathrm{mm}^{3}$ on microscopic examination. Because of hydrocephalus was noticed EVD tube was inserted. Vancomycin and meropenem combination therapy was started. $P$. aeruginosa was isolated in CSF culture and vancomycin therapy was stopped. $P$. aeruginosa was persisted in CSF cultures at the 5th day of antibiotic therapy, therefore ciprofloxacin [intravenous and IVT (1 mg/kg/day)] was added to IV meropenem therapy according to the antibiotic susceptibility test results. CSF cultures remained sterile after 3 weeks intravenous and 10 days IVT ciprofloxacin therapies.

\section{Discussion and Conclusions}

The principles of antimicrobial treatment for CSF shunt infections are mostly the same as those for the treatment of acute bacterial meningitis. Management of CNS shunt infections should include removal of the infected device, external drainage, parenteral appropriate antibiotics, and shunt replacement once the CSF is sterile.2 IVT antibiotic therapy might become necessary in cases unresponsive to intravenous therapy and presence of highly resistant organisms sensitive to antibiotics with poor CSF penetration. ${ }^{2-5}$ No antimicrobial agent has been approved by the US Food and Drug Administration for IVT use. However recommended antimicrobial agents that are administered by intraventricular route are: Gentamicin, Amikacin, Colistin, Teicoplanin, Vancomycin, Polymyxin B
Tobramycin.2 Bactericidal antibiotics with good CSF penetration should be chosen in treatment of CNS infections. Prolonged hospitalization and inappropriate antibiotic selection provide a basis for multidrug-resistant infections. Schönvald et al. showed, 18 adult patients who had gram negative bacterial meningitis, had treated successfully with intravenous ciprofloxacin. ${ }^{6}$ The use of quinolones is not preferred in children due to their potential side effects. However it is reported that quinolones could also be used in children with some restricted indications such as chronic recurrent pyelonephritis, CNS shunt infections, exacerbations of cystic fibrosis. ${ }^{7-9}$ Because these agents have not been studied in infants and children with bacterial meningitis, they should only be considered in these patients who are not responding to standard therapy.

In the literature, there are several reports that intravenous quinolones are successfully used in children with meningitis. ${ }^{10-12}$ However we have only found two reports about IVT ciprofloxacin therapy in children and also in adults. In one of them with the diagnosis of VP shunt meningitis, IVT ciprofloxacin had to be stopped because of myoclonic convulsion was observed. ${ }^{13}$ In the second report, two infants with the diagnosis of ventriculitis were treated with IVT ciprofloxacin sucessfully. 14

External ventricular drainage tube placement enables decreasing intracranial pressure and monitorization of the infection markers. To provide bacterial eradication, it is necessary to have drug concentration in CSF being 10 fold more than the MIC value of the pathogen. Penetration of antibiotics could be insufficient due to the occlusions within the ventricle caused by the inflammation, so higher levels of drug could be achieved by direct administration of the drug into the ventricle. There is no standardized approach to IVT antibiotic dosing. ${ }^{15-16}$ However IVT drug doses are determined empirically as there is no enough study investigating the pharmacokinetics and pharmacodynamics of the drugs being administered by this route. According to limited number of studies, IVT antibiotics should generally be administered once a day and then EVD should be closed for 30-60 minutes. In our cases because of the lack of studies, we administered the ciprofloxacin $1 \mathrm{mg} / \mathrm{kg}$ once a day intaventricularly and EVD was closed for one hour.

In our four cases with CNS infections ciprofloxacin therapy was administered according to the antimicrobial susceptibility test results and absence of improvement by standard antibiotic therapies. Multidrug-resistant gram negative microorganisms were causative agent in three of them and Enterococcus faecium was the causative agent in one case.
Optimal therapy for vancomycin-resistant $E$. faecium meningitis has not been well established. Intravenous linezolid is an acceptable antibiotic choice. ${ }^{17}$ This problem underscores the need to investigate new combinations of effective therapy. Landman et al. found that combinations of ciprofloxacin plus ampicillin or novobiocin have significant in vitro activity against many multidrug-resistant enterococci.18 We had administered ciprofloxacin and tetracycline combination therapy successfully. At that time linezolid was unavailable in our country, for this reason we could not administer that agent.

Shunt infections with more virulent pathogens such as gram-negative bacilli warrant longer therapy; at least 14 to 21 days. ${ }^{2}$ The optimal duration of treatment of meningitis with quinolones is unknown. For this reason we have preferred longer therapy for our patients.

As a conclusion, IVT ciprofloxacin therapy is an important novel approach to treat CNS infections with multidrug-resistant microorganisms.

\section{References}

1. Segal SM, Mariano N, Qavi A, et al. Succesfull treatment of ceftazidime-resistant Klebsiella pneumonia ventriculitis with intravenous meropenem and IVT polymyxin B: case report and review. Clin Infect Dis 1999;28:1134-8.

2. Tunkel AR, Hartman BJ, Kaplan SL, et al. Practice guidelines for the management of bacterial meningitis. Clin Infect Dis 2004;39:1267-84.

3. Wen DY, Bottini AG, Hall WA, Haines SJ. IVT use of antibiotics. Neurosurg Clin N Am 1992;3:343-54.

4. Schreffler RT, Schreffler AJ, Wittler RR. Treatment of cerebrospinal fluid shunt infections: a decision analysis. Pediatr Infect Dis 2002;21:632-6.

5. Wen DY, Bottini AG, Hall WA, Haines SJ. Infections in neurologic surgery. The IVT use of antibiotics. Neurosurg Clin N Am 1992;3:343.

6. Schonwald S, Geus I, Lisic M, et al. Ciprofloxacin in the treatment of gramnegative bacillary meningitis. Am J Med 1989;87:248S-9S.

7. Black A, Redmont AOB, Steen HJ, Oborska IT. Tolerance and safety of ciprofloxacin in pediatric patients. J Antimicrob Chemother 1990; 26:25-9.

8. Hampel B, Hullmann R, Schmidt K. Ciprofloxacin in pediatrics, worldwide clinical experience based on compassionate use-safety report. Pediatr Infect Dis J 1997;16:127-9. 
9. Schaad UB, Sander E, Wedgwood J, Schaffner T. Morphologic studies for skeletal toxicity after prolonged ciprofloxacin therapy in two juvenile cystic fibrosis patients. Pediatr Infect Dis J 1992;11:10479.

10. Fomda BA, Charoo BA, Bhat JA, et al. Recurrent meningitis due to Salmonella enteritidis: a case report from Kashmir India. Indian J Med Microbiol 2012;30:4746.

11. Kiwanuka JP, Mwanga J. Childhood bacterial meningitis in Mbarara Hospital, Uganda: antimicrobial susceptibility and outcome of treatment. Afr Health Sci 2001;1:9-11.
12. Krcméry $\mathrm{V}$ Jr, Filka $\mathrm{J}$, Uher $\mathrm{J}$, et al. Ciprofloxacin in treatment of nosocomial meningitis in neonates and in infants: report of 12 cases and review. Diagn Microbiol Infect Dis 1999;35:75-80.

13. Celebi S, Hacimustafaoglu M, Kurtoglu B, Ildirim . Convulsion due to IVT use of ciprofloxacin (Case report). ANKEM Derg 2002;16:22-4.

14. Bilgen H, Ozek E, Erkan E, et al. Treatment of multiresistant gram negative ventriculitis with IVT ciprofloxacin. Marmara Med J 1998:11-2.

15. Wald SL, McLaurin RL. Cerebrospinal fluid antibiotic levels during treatment of shunt infections. J Neurosurg 1980;52:41.
16. James HE, Wilson HD, Connor JD, Walsh JW. IVT cerebrospinal fluid antibiotic concentrations in patients with IVT infections. Neurosurgery 1982;10:50.

17. Hachem R, Afif C, Gokaslan Z, Raad I. Successful treatment of vancomycin-resistant Enterococcus meningitis with linezolid. Eur J Clin Microbiol Infect Dis 2001;20:432.

18. Landman D, Mobarakai NK, Quale J. M. Enterococcus faecium resistant to ampicillin, Novel antibiotic regimens against vancomycin, and gentamicin. Antimicrob Agents Chemother 1993;37:1904. 